ИЗВЕСТИЯ АКАДЕМИИ НАУК ЭСТОНСКОИ ССР. ТОМ 32 ХИМИЯ. 1983. № 1

\title{
ПОЛУЧЕНИЕ ТРИХЛОРИДОВ РЕДКОЗЕМЕЛЬНЫХ ЭЛЕМЕНТОВ
}

\author{
(Представил О. Киррет)
}

В последние годы трихлориды редкоземельных элементов (Р3Э) приобрели важное значение в ряде областей техники, в частности, в процессах синтеза каталитических систем, в металлургии редкоземельных металлов и т. д. Отсутствие технологии, позволяющей получать трихлориды Р3Э приемлемой чистоты и в достаточных количествах, препятствует их широкому использованию. Это объясняется рядом обстоятельств. До недавнего времени потребность в трихлоридах Р3Э определялась лишь исследовательскими целями. Для их синтеза было разработано много методов, в основе которых лежат либо процессы хлорирования оксидов РЗЭ различными хлорирующими агентами, либо те или иные варианты обезвоживания кристаллогидратов хлоридов РЗЭ. Выбор какого-либо метода получения трихлоридов РЗЭ определялся прежде всего возможностями самих исследователей и другими субъективными факторами. При этом количество получаемого за цикл продукта, как правило, не превышало полутора десятков граммов. Попытки получения трихлоридов Р3Э в укрупненных масштабах (в кг и более) способами и приемами, используемыми в исследовательской практике, не дали положительных результатов. Это связано с тем, что практическое использование в технологии ряда методов характеризуется наличием трудностей принципиального характера, а другие не были реализованы из-за недостаточной изученности. В данной работе делается попытка критически оценить имеющийся в этой области опыт и наметить наиболее целесообразные пути, которые дали бы возможность в дальнейшем разработать технологию получения трихлоридов Р3Э в промышленных масштабах.

Одно из принципиальных отличий трихлоридов Р3Э от хлоридов других редких металлов ( $\mathrm{Ti}, \mathrm{Zr}, \mathrm{Nb}, \mathrm{Ta}$ и др.) - то, что при обычных температурах хлорирования $\left(\sim 1000^{\circ} \mathrm{C}\right)$ они практически нелетучи и находятся в остатке от хлорирования в виде плава. Поэтому исходные реагенты должны быть достаточно чистыми, а условия проведения хлорирования (температура, состав газовой фазы, аппаратура и др.) - обеспечивать полноту протекания процесса и исключать загрязнение конечных продуктов. По этой причине традиционные методы хлорной металлургии редких металлов, предусматривающие использование брикетированной шихты оксидов, не позволяют получать трихлориды приемлемой чистоты, так как стекающий из зоны хлорирования плав сильно загрязняется растворимыми в нем оксихлоридами и углеродсодержащими продуктами.

Более эффективными оказались приемы обработки оксидов Р3Э газообразными хлорирующими агентами в среде расплавленных хлоридов щелочных металлов при $800-900^{\circ}[1,2]$. При этом, чтобы избежать загрязнения продукта углеродом, в качестве хлорирующего агента используют хлористый водород или смесь хлора с аммиаком. В резуль- 
тате хлорирования образуется плав хлоридов щелочных и редкоземельных металлов, который более устойчив к окислению и значительно менее гигроскопичен при хранении, чем чистый трихлорид Р3Э. Основным препятствием в реализации этого процесса являются трудности аппаратурного оформления, обусловленные агрессивностью расплава и содержанием в газовой фазе продуктов высокотемпературного взаимодействия в системе $\mathrm{H}_{2} \mathrm{O}-\mathrm{HCl}$. Кроме того, получаемый продукт представляет собой не чистый трихлорид, а смесь хлоридов щелочных и редкоземельных металлов примерно в равных весовых отношениях, а это вносит определенные ограничения в его применение.

Другие варианты получения трихлоридов Р3Э в расплаве связаны с использованием относительно низкоплавких хлорирующих агентов $\left(180-250^{\circ}\right)$, легко отгоняемых по окончании процесса, например, пятихлористого фосфора или его смеси с хлоридами алюминия, железа и других элементов, используемых для стабилизации хлорирующей системы [ $\left.{ }^{3}\right]$, либо гидрохлоридаминов . (метил-, этил-, диэтиламин, пиридин и др.) $\left[{ }^{4}\right]$. Основной недостаток этих методов заключается в том, что получаемые трихлориды Р3Э необходимо перегонять, так как они содержат некоторое количество нелетучих соединений фосфора, алюминия, продуктов пиролиза гидрохлоридаминов. Кроме того, высокая стоимость хлорирующих агентов позволяет отнести эти способы скорее к препаративным.

Обширная группа способов предусматривает обработку оксидов РЗЭ газообразными хлорсодержащими агентами при соответствующих температурах. Основу этих процессов составляет гетерогенная реакция с участием твердой и газовой фаз. В качестве хлорирующих агентов рекомендуют использовать хлор в смеси с углеродом $\left[{ }^{5-8}\right]$, хлористый водород $\left.{ }^{9}\right]$, фосген $\left.{ }^{10}\right]$, четыреххлористый углерод и различные хлорпроизводные серы в смеси с хлором [5, 11-16]. Отличительная особенность этих методов заключается в том, что даже в технологических опытах количество оксидов Р3Э составляет 5-10 г, а расход хлорирующего агента в несколько десятков раз выше теоретически необходимого. Тем не менее, продолжительность этих процессов в статических условиях достаточно велика - несколько часов. Замена одного газового реагента на другой существенно не изменяет показателей процесса, а лишь влияет на выбор температуры, которая в целом остается достаточно высокой $\left(450-700^{\circ}\right)$. Проведение процесса в подвижном слое - сложная задача, неизбежно сопряженная с большим пылеуносом и необходимостью создания системы пылеулавливания. В то же время использование брикетированной шихты предполагает введение связующего материала органического происхождения, который при температуре процесса образует твердые углерод- и серусодержащие продукты и загрязняет получаемый трихлорид. Кроме того, при использовании брикетированной шихты не достигается полноты хлорирования оксидов. Так, при обработке углеродсодержащих брикетов кубической формы с размером ребра 20 мм четыреххлористым углеродом в смеси с хлором в течение 15 ч при 500 $600^{\circ}$ степень хлорирования не превышала $70 \%$. Главная причина неудовлетворительных результатов использования как порошкообразных, так и брикетированных оксидов Р3Э связана с кинетическими факторами, резким уменьшением газопроницаемости реакционной массы вследствие образования слоя твердых продуктов реакции.

Учитывая эти трудности, отдельные исследователи пытались применять вместо оксидов Р3Э оксалаты, карбонаты, а также чистые редкоземельные металлы [16-18]. Действительно, в некоторых случаях при использовании небольших навесок (не более 10 г) были получены положительные результаты. Однако в целом недостатки, свойственные процессам хлорирования газообразными хлорирующими агентами при 
проведении их в укрупненных масштабах, сохраняются. Кроме того, при использовании в качестве исходных реагентов редкоземельных металлов $\left.{ }^{18}\right]$ задача их получения сама по себе представляет значительные трудности. Поэтому этот вариант годится лишь для получения трихлоридов в препаративных целях.

Существенными преимуществами перед газообразными реагентами при хлорировании оксидов Р3Э обладает хлорид аммония, позволяющий распространить процесс хлорирования на весь объем реакционной массы. Однако до сих пор отсутствие достоверных сведений по химизму, кинетике и другим параметрам протекания процесса $\left[{ }^{19-23}\right]$ не позволяло реально оценить возможности этого метода. По этой причине условия проведения процесса подбирались эмпирически и на получение конечного продукта уходили десятки часов. Опубликованные в последнее время исследования по термическим превращениям в системе $\mathrm{Ln}_{2} \mathrm{O}_{3}-\mathrm{NH}_{4} \mathrm{Cl}[24-27]$ позволили установить, что в процессе взаимодействия оксидов Р3Э с хлоридом аммония образуется комплексный хлорид состава $\left(\mathrm{NH}_{4}\right)_{3} \mathrm{LnCl}_{6}$. Последующие превращения в системе связаны с его разложением и выделением в газовую фазу хлорида аммония и продуктов его диссоциации, которые, однако, практически не взаимодействуют с остаточной оксидной фазой. Поэтому для достижения полноты хлорирования с учетом частичной сублимации хлорида аммония и уноса его из реакционной зоны молярное соотношение исходных компонентов в шихте $\mathrm{NH}_{4} \mathrm{Cl} / \mathrm{Ln}_{2} \mathrm{O}_{3}$ должно быть не менее 13,5-14. Процесс хлорирования протекает достаточно интенсивно. Так, в интервале температур $260-340^{\circ}$ хлорирование длится 20-30 мин. Образующийся комплексный хлорид значительно более устойчив к гидролизу и менее гигроскопичен при хранении, чем чистый трихлорид. Это позволяет проводить процесс в потоке осушенного воздуха или при небольшом разрежении. Для предотвращения образования оксихлоридной фазы при разложении $\left(\mathrm{NH}_{4}\right)_{3} \mathrm{LnCl}_{6}$ отгонять хлорид аммония необходимо либо в среде инертного газа, либо при вакуумировании системы. В лабораторных условиях в трубчатой печи этим методом за $2-2,5$ ч были получены партии трихлоридов РЗЭ в количестве $1,1-1,3$ кг.

Наряду с хлорированием оксидов широкое распространение получили различные методы обезвоживания кристаллогидратов хлоридов РЗЭ. Однако обезвоживание их термическим разложением представляет серьезные затруднения, так как сопровождается гидролизом хлоридной основы кристаллогидрата с образованием кислородсодержащих соединений. С учетом этого делались попытки перевести кристаллогидраты в спиртосольваты $\left.{ }^{28}\right]$ либо в комплексные соединения с другими органическими лигандами, например, комплексы с мочевиной [29]. Но эксперименты показали, что условия их выделения, существования и разложения не позволяют полностью исключить из них воду. В результате получаемый трихлорид содержит 0,5-1,5 молей воды. Совершенствования же этих способов можно-добиться только путем использования исключительно чистых реагентов и герметизации системы на всех этапах процесса обезвоживания, что практически исключает перспективу использования этих методов в укрупненных масштабах.

При термическом разложении кристаллогидратов хлоридов РЗЭ для предотвращения гидролиза рекомендуется использовать вакуум [30], среду хлорирующего агента (хлористый водород $[31-36]$ или хлорид аммония $[32,37]$ ) или смесь их с хлоридами щелочных металлов, например, хлоридом калия $\left.{ }^{38}\right]$. Однако из-за недостаточной изученности процесса термического разложения кристаллогидратов хлоридов Р3Э, что в значительной мере связано с несовершенством методик исследования и односторонним подходом к интерпретации результатов, на выбор условий обезвоживания влияли случайные факторы. Ввиду этого темпера- 
тура проведения процесса, количество хлорирующего агента и состав газовой фазы подбирались эмпирически, а обезвоживание длилось десятки часов.

В более поздних работах [39-43], проведенных с применением различных методов исследования, было установлено, что по характеру термического разложения кристаллогидраты хлоридов Р3Э делятся на две группы: цериевую (от лантана до неодима) и иттриевую (от самария до лютеция, включая и иттрий). Термолиз кристаллогидратов хлоридов цериевой группы в среде инертного газа, осушенного воздуха протекает ступенчато, на стадии низших кристаллогидратов по типу простой диссоциации, с образованием при $150-170^{\circ}$ безводного продукта. В аналогичных условиях термическое разложение кристаллогидратов хлоридов иттриевой группы протекает в более высокотемпературной области и осложняется гидролизом за счет выделяющихся при дегидратации паров воды. Гидролиз усиливается на стадии диссоциации моногидрата, который обладает индивидуальной структурой и устойчив в довольно широком интервале температур. Например, $\mathrm{DyCl}_{3} \cdot \mathrm{H}_{2} \mathrm{O}$ устойчив в интервале температур $170-213^{\circ}$. В результате конечным продуктом обезвоживания является не трихлорид, а основные хлориды $\mathrm{Ln}(\mathrm{OH}) \mathrm{Cl}_{2}, \operatorname{Ln}(\mathrm{OH})_{2} \mathrm{Cl}$ либо их смеси. Проведение термолиза кристаллогидратов хлоридов иттриевой группы в вакууме несколько уменьшает степень гидролиза за счет смещения дегидратации в более низкотемпературную область и уменьшения парциального давления паров воды в массе кристаллогидрата. Однако даже для малых навесок $(0,45$ г), размещенных тонким слоем, содержание безводной хлоридной фазы в конечном продукте не превышало $50 \%$.

Введение в обезвоживаемую систему добавок хлорида аммония, как было установлено [42], приводит к тому, что на стадии образования низших кристаллогидратов вследствие ненасыщенности валентных связей хлорид аммония координируется хлоридной основой кристаллогидрата с образованием гидратированного комплексного хлорида $\left(\mathrm{NH}_{4}\right)_{3} \mathrm{LnCl}_{6} \mathrm{X}$ $\times n \mathrm{H}_{2} \mathrm{O}$. При этом температура обезвоживания кристаллогидратов хлоридов цериевой группы не меняется. Для иттриевой группы образование такого комплекса препятствует стабилизации моногидрата индивидуальной структуры. Вследствие этого термическое разложение кристаллогидратов хлоридов иттриевой группы приобретает вид простой диссоциации. В зависимости от индивидуальных особенностей характера дегидратации кристаллогидратов соответствующих Р3Э температура обезвоживания снижается на $50-80^{\circ}$. Однако в целом степень гидролиза уменьшается незначительно. Замена хлорида аммония на хлориды щелочных металлов, в частности, на хлорид калия, как было установлено, не приводит к образованию каких-либо соединений в обезвоживаемой системе и не влияет на температуру разложения и степень гидролиза кристаллогидрата.

Термолиз кристаллогидратов хлоридов Р3Э иттриевой группы в среде, содержащей хлористый водород, заканчивается образованием безводных продуктов при $185-240^{\circ}[41,44]$. При этом хлористый водород не является хлорирующим агентом, а необходим для подавления гидролиза. Следовательно, обезвоживание кристаллогидратов хлоридов РЗЭ иттриевой группы термическим разложением с целью получения их трихлоридов необходимо проводить только в среде, содержащей хлористый водород.

При обезвоживании кристаллогидратов хлоридов Р3Э в промышленных масштабах процесс необходимо проводить в условиях кипящего слоя. Это позволяет создать достаточно интенсивный массообмен и избежать локального повышения парциального давления паров воды, при котором превышается значение константы равновесия $\left(K_{p}\right)$ гидролиза 
для данной стадии разложения кристаллогидрата и образуется гидролизованный продукт. В лабораторных условиях в аппарате кипящего слоя, с диаметром рабочей камеры 150 мм, в газовом потоке осушенного воздуха за $1-1,2$ ч получали $0,8-0,85$ кг трихлоридов РЗЭ цериевой группы. Кристаллогидраты хлоридов иттриевой группы обезвоживали в потоке хлористого водорода. Время обезвоживания составляло $1,7-1,9$ ч, количество получаемого безводного продукта $-0,7-0,8$ кг.

Рассмотрев имеющийся опыт получения трихлоридов Р3Э, можно сделать вывод о серьезных трудностях, возникающих при практической реализации хлорирования оксидов РЗЭ в расплаве. В одних случаях это связано с высокими температурами, отсутствием возможности получения чистого продукта, агрессивностью парогазовой смеси, как это имеет место при хлорировании в расплаве хлорида калия, в других - с агрессивностью самого расплава, использованием дорогостоящих реагентов, а также с дополнительными условиями, в том числе с необходимостью дистилляции получаемого продукта. Получение безводных трихлоридов Р3Э путем хлорирования оксидов различными парообразными хлорирующими агентами, как было показано выше, невозможно осуществить из-за отсутствия реальных технических решений аппаратурного оформления этих процессов, связанного с большим расходом хлорирующего агента, пылеуносом дисперсного порошка, наличием в трихлоридах твердых продуктов пиролиза (углерод) и серусодержащих компонентов и т. д.

Видимо, наиболее реально - получение трихлоридов РЗЭ в промышленных масштабах путем термического разложения их кристаллогидратов или хлорирования оксидов Р3Э хлоридом аммония. Эти способы дают возможность получать трихлориды при достаточно низких температурах $\left(250-350^{\circ}\right)$, что упрощает аппаратурное оформление процесса. Необходимые реагенты распределены равномерно по всему объему реакционной массы. Проведенные укрупненные лабораторные опыты с использованием этих методов дали положительные результаты.

\section{ЛИ Т Е Р А У Р А}

1. Reinhard, J., Naumann, D. Die Bildung von Ceroxidchlorid bei der Hydrolyse von $\mathrm{CeCl}_{3}$ in Alkalichloridschmelzen, - Z. Chem., 1967, N 7, 317.

2. Назаров Ю. Н., Крохин В. А. Состояние и перспективы развития хлорной металлургии. - Цветные металлы, 1981, № 9, 68-70.

3. Нисельсон Л. А., Лызлов Ю. Н., Третьякова К. А. Синтез безводных хлоридов редкоземельных элементов, иттрия и скандия. - Ж. неорган. хим., 1975, 20 , № 9, 2362-2367.

4. Didchenko, $R$. Preparation of anhydrous chlorides of cerium and thorium. - Trans. Met. Soc. AIME, 1959, 215, 401-403.

5. Нвашенцев Я. Н., Стоянова М. Н. О взаимодействии окиси европия с некоторыми хлорирующими реагентами. - Ж. неорган. хим., 1968, 13, № 7, 1894-1898.

6. Hartley, F. R., Wylie, A. W. Preparation of rare-earth chlorides. - Nature, 1948, 161,241 .

7. Gut, R., Gruen, D. M. The scandium chloride-cesium chloride phase diagram. J. Inorg. Nucl. Chem., 1961, 21, 259-261.

8. Campbell, T. T. Preparation of some rare earth. - BM-RI-5880, 1960, 82, 736-737.

9. Templeton, D. H., Carter, J. F. The crystal structure of yttrium trichloride and similar compounds. - J. Phys. Chem., 1954, 58, N 11, 940-944.

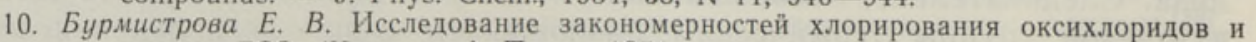
окислов Р3Э. (Канд. дис.). Пермь, 1974.

11. Johnson, K. E., Mackenzie, J. R. Anhydrous chlorides of some rare earth. - J. Inorg. Nucl. Chem., 1970, 32, 43-48.

12. Stubblefield, C. T., Eyring, L. On the reaction of European dichloride with solutions of hydrochloric acid. - J. Amer. Chem. Soc., 1955, 77, N 11, 3004-3006.

13. Miller, J. F., Miller, S. E., Himes, R. C. Preparation of anhydrous rare earth chlorides for physicochemical studies. - J. Amer. Chem. Soc., 1959, 81, N 17, 4449-4451.

14. Поляченок О. Г., Новиков Г. Н. Система $\mathrm{ScCl}_{3}-\mathrm{Sc}$. Ж. неорган. хим., 1963, 8, № 12, 2819-2921. 
15. Поляченок О.Г., Новиков Г. И. Давление насыщенного пара $\mathrm{SmCl}_{2}, \mathrm{EuCl}_{2}, \mathrm{YbCl}_{2}$ - Ж. неорган. хим., 1963, 8, № 12, 2631-2634.

16. Новиков Г. И., Поляченок О. Г. Исследование систем $\mathrm{NdCl}_{3}-\mathrm{Nd}, \mathrm{PrCl}_{3}-\mathrm{Pr}$. - Ж. неорган, хим., 1963, 8, № 12, 1053-1059.

17. Новиков Г. И., Толмачева В. Д. К вопросу о получении безводных хлорндов редкоземельных элементов. - Ж. прикл. хим., 1965, 38, № 5, 1160-1161.

18. Carter, F. L., Murray, J. F. Preparation of the anhydrous rare earth trichlorides, tribromides and triiodides. - Mat. Res. Bull., 1972, 7, 519-524.

19. Reed, J B., Hopkins, B. S., Andrieth, L. M. Preparation of anhydrous rare earth compounds by the action of fused and solid «ammonium» salts on the oxides. J. Amer. Chem. Soc., 1935, 57, 1159-1160.

20. Kiess, N. H. Preparation of anhydrous single crystals of rare earth halides. J. Res. Nat. Studies, 1963, 67Â, 343-345.

21. Mochinaga, J., Irisawa, K. Phase diagrams of $\mathrm{YCl}_{3}-\mathrm{KCl}, \mathrm{YCl}_{3}-\mathrm{NaCl}_{3}, \mathrm{YCl}_{3}-\mathrm{KCl} \cdot \mathrm{NaCl}$ systems and densities of their molten mixtures. - Bull. Chem. Soc. Japan, 1974, 42, N 2, 364-367.

22. Крестов Г. А., Кобенин В. А., Семеновский С. В. Новый метод получения безводных хлоридов РЗЭ. - Изв. ВУЗов. Химия и хим. технол., 1971, 14, вып. 3, $462-464$.

23. Нвашенцев Я. И., Стоянова М. И. К хлорированию окислов цериевой подгруппы хлористым водородом и хлористым аммонием. - В сб.: Обогащение и металлургия цветных металлов. Красноярск, 1969, вып. 3, 103-112.

24. Абрамец В. А., Варфоломеев М. Б., Жаворонкова Л. Г. Двойные хлориды аммония и редкоземельных элементов $3 \mathrm{NH}_{4} \mathrm{Cl} \cdot \mathrm{LnCl}_{3}(\mathrm{Ln}=\mathrm{P} 3 Э$ в ряду $\mathrm{Sm}-\mathrm{Ln}, \mathrm{Y})$. Ж. неорган. хим., 1980, 25, № 3, 717-720.

25. Абрамец В. А., Варфоломеев М. Б., Жаворонкова Л. Г., Петренко Л. Я., Шамpaй $H$. Б. Двойные хлориды аммония и редкоземельных элементов $2 \mathrm{NH}_{4} \mathrm{Cl} \cdot \mathrm{LnCl}_{3}$ $(\mathrm{Ln}=\mathrm{La}-\mathrm{Tb})$. - Ж. неорган. хим., 1981, 26, № 6, 1531-1534.

26. Барышников Н. В., Полонский А. В., Лапшина Н. Е. Взаимодействие оксида иттрия с хлористым аммонием. - Ж. неорган. хим., 1981, 26, № 12, 3236-3240.

27. Полонский А. В., Барышников Н. В., Ахелик В. Р. Взаимодействие оксида лантана с хлористым аммонием. - Ж. неорган. хим., 1982, 27, № 2, 531-533.

28. Ревзин $\Gamma$. E. Безводные хлориды редкоземельных элементов и скандия. - В сб.: Методы получения химических реактивов и препаратов. М., 1967, вып. 1, 16-21.

29. Аиимкулова Г. А., Сулайманкулов К., Турдалиев Ш. Т., Ногоев К. Равновесие в системе хлорид иттрия-мочевина-вода при $30^{\circ} \mathrm{C}$ - Ж. неорган. хим., 1973, 18, № 7, 2011-2013.

30. Нльин В. К., Кренев В. А., Евдокимов В. И. Термическое разложение гексагидратов хлоридов самария, европия, иттербня в вакууме. - Ж. неорган. хим., 1972 , 17, № 10, $2853-2854$.

31. Kleinheksel, J. H., Kremers, H. C. The preparation and properties of some anhydrous rare earth chlorides. - J. Amer. Chem. Soc., 1928, 50, 959-967.

32. Спеддинг Ф. Х., Даан А. Х. Редкоземельные металлы. М., 1965.

33. Mroczkowski, S. Preparation of single crystals of $\mathrm{EuCl}_{3}$ and related polyvalent halides. - J. Crystals Growth, 1970, N 6, 147-150.

34. Iantsch, J., Grubitsch, H., Hoffmann, F., Alber, H. Ober die Iodide der Ceriterdenelemente und die Neubestimmung der Schmelzpunkte der Chloride. - Z . Anorg. Allg. Chem., 1930, 185, 49-64.

35. Daane, A. H., Spedding, F. H. Preparation of yttrium and some heavy rare earth metals. - J. Electrochem. Soc., 1953, 100, N 10, 442-444.

36. Harrison, E. E. Vapour pressures of some rare earth halides. - J. Appl. Chem., 1952, 2, N 10, 601-602.

37. Taylor, M. D., Carter, C. P. Preparation of anhydrous lanthanide halides, especially iodides. - J. Inorg. Nucl. Chem., 1962, 24, 387-391.

38. Кориунов Б. Г., Нихамкин А. А. Приготовление солевых расплавов, содержащих хлориды редкоземельных элементов. - В сб.: Исследование в области химии и технологии минеральных солей и окислов. М.-Л., 1965, 312-313.

39. Haeseler, J., Matthes, F. Uber den thermischen Abbau der Chloridhydrate der Elemente der seltenen Erden. - J. Less-Common Metals, 1965, N 9, 133-151.

40. Зеликман А. Н., Барышников Н. В., Хохлов А. И., Волков В. Т. Исследование термического разложения кристаллогидратов хлоридов лантана и неодима. Изв. ВУЗов. Цвет. металлургия, 1971, 14, вып. 6, 89-94.

41. Барышников Н. В., Полонский А. В., Хохлов А. И. Термическое разложение гексагидрата хлорнда иттрия. - Ж. неорган. хим., 1975, 20, № 3177-3182.

42. Полонский А. В., Барышников Н. В., Воскресенская Л. А. Особенности дегидратащии $\mathrm{YCl}_{3} \cdot 6 \mathrm{H}_{2} \mathrm{O}$ в присутствии хлористого аммония. - Ж. неорган. хим., 1976, 21, № 2, 317-320.

43. Барышников Н. В., Зеликман А. Н., Полонский А. В., Хохлов А. И., Овсянникова $\mathrm{H}$. В. Исследование термического разложения $\mathrm{EuCl}_{3} \cdot 6 \mathrm{H}_{2} \mathrm{O}$ методом высокотемпературной инфракрасной спектроскопии. - В сб.: Научные труды Гиредмета. М., 1977, № 74, 49-54. 
44. Полонский А. В., Барышников Н. В., Воскресенская Л. А. Исследование процессов сорбции и десорбции паров воды трихлоридом иттрия. - Ж. прикл. хим., 1981, 54, № 8, 1818-1821.

\section{Институт химии \\ Академии маук Эстонской ССР}

Поступила в редакцию

16/VI 1982

\section{A. POLONSKI}

\section{HARULDASTE MULDELEMENTIDE KLORIIDIDE SAAMINE}

Artikkel sisaldab haruldaste muldelementide (HME) kloriidide saamisviiside (HME oksiidide jm. ühendite kloorimine, HME kloriidide hüdraatide dehüdreerimine) kriitilise analüüsi. Tootmisel soovitatakse rakendada oksiidide kloorimist ammooniumkloriidiga ja kloriidide hüdraatide termilist lagundamist. Nimetatud meetodite ulatuslikul kontrollimisel on saadud positiivseid tulemusi.

\section{A. POLONSKI}

\section{PREPARATION OF RARE EARTH TRICHLORIDES}

The methods of obtaining rare earth trichlorides (chlorination of oxides and other rare earth compounds by chlorinating agents; dehydration of rare earth chloride hydrates) are under consideration. For obtaining rare earth trichlorides we suggest either chlorination of rare earth oxides by ammonium chloride or thermal decomposition of rare earth chloride hydrates. These methods are checked in terms of their commercial application. 